\title{
Students' Self-Efficacy and Self-Rating Scores as Predictors of Their Academic Achievement
}

\author{
Kingsley Chinaza Nwosu \\ Department of Educational Foundations, Nnamdi Azikiwe University, PMB 5025, Awka, Nigeria \\ kingsmcjudec@yahoo.co.uk \\ Romy 0. Okoye \\ Department of Educational Foundations, Nnamdi Azikiwe University, PMB 5025,Awka, Nigeria \\ romyokoye@yahoo.com
}

\section{Doi:10.5901/jesr.2014.v4n3p223}

\section{Abstract}

This study set out to establish the predictive power of students' self-efficacy and self-rating scores on undergraduate students' academic achievement in a Psychology course (psychology of Learning). The correlational research design was adopted and all the 133 sophomores in the Continuing Education Programme (CEP) of the Nnamdi Azikiwe University, Awka, Nigeria who registered the course were sampled for the study. The instruments used were a domain-specific self-efficacy questionnaire and a semester examination developed by the researchers. The regression analysis showed that self-efficacy and self-rating did not combine to predict students' achievement; however, considering their relative contribution, students' self-rating scores predicted their academic performance more than their self-efficacy. Furthermore, students' self-efficacy and self-rating scores were related, but only students' self-rating scores were related to their academic achievement. It was concluded that large selfefficacy is not enough to counter limited knowledge and competence.

Keywords: self-efficacy, self-rating, expectancy outcome, self-grading, social learning, self-appraisal, confident individuals

\section{Introduction}

Contemporary educational practices point in the direction of making the learner a self-dependent and problem-solving learner not just being able to recall facts but also judge his abilities and process of arriving at answers to problems. Effective study demands students' accurate appraisal of their knowledge of the to-be- tested material and appropriate allocation of study time and cognitive resources (Tassone, 2001). This draws our attention to the fact that overt students' achievements depend on invisible factors such as motivation, academic self- concept, academic self-efficacy, performance expectancy, etc. and that human beings are not only cognitive individuals but also social persons with beliefs, emotions and views that influence their development as learners, and as such a person's behavior and choices, when confronted with a task, are determined more by his or her beliefs or personal theories, rather than by his or her knowledge of specific tasks (Pajares, n.d). This is in line with Akanwa and Okonkwo's (2013) assertion that people's interpretation of the consequence of the result of their own behavior informs and alters their environments and the personal factors they possess, which, in turn, inform and alter subsequent behavior. They noted that of all self-referent thoughts, that none is more important than the beliefs people hold of themselves which have been referred to as selfefficacy. Self-efficacy beliefs have been considered to have enormous influence on how people think, feel, get motivated, and act (Zulkosky, 2009) and is considered as the major component of Bandura's (1986) Social Learning theory which stresses that behavior is shaped by self (Harrison, Rainer, Hochwarter \& Thompson, 1997).

Self-efficacy has its origin in Bandura's Social learning theory or renamed later Social Cognitive theory in 1986 (Brosnan, 1998; Schunk \& Pajares, nd; Lennon, 2010; Zulkosky, 2009) which is a theoretical framework regarded as "triadic reciprocal determinism" and widely accepted in predicting individual behavior using several key concepts and identifying methods in which behavior can be modified or changed (Shu, Tu, Wang, 2011; Stretcher, Devellis, Becker, \& Rosenstock, 1986). Social Learning theory stresses that human development is a dynamic interplay of one's behavior, personal factors and environmental influences (Akanwa \& Okonkwo, 2013; Schunk \& Pajares, 2002).

Self-efficacy is one of the theoretical constructs that signaled a significant departure from behaviorist schools of 
thought, which dominated behavioral science for decades and has been a major focus of theoretical and empirical scholarship which have shown that variations in performance could now be attributed, in part, to differences among people in their beliefs and perceptions about their ability, rather than differences among people in their reinforcement histories (Lennon, 2010). Self efficacy beliefs, according to Hall and Vanice (2010), are 'thoughts or ideas people hold about their abilities to perform those tasks necessary to achieve a desired outcome'. Bandura (1997) defined self-efficacy as a belief in one's own ability to organize and perform certain tasks. It refers to learners' beliefs about their capabilities of carrying out a task in which they cognitively pose such questions like 'can I do it or not' (Min-Hsun \& Pey-Chewn, 2012). Every individual has a conviction about his ability to carry out a particular activity and these beliefs influence the way he thinks and feels, which can facilitate or restrain his actions. Clark, and Dodge (1999) noted that self-efficacy is a part of reciprocal process that determines behavior and that assessing just the level of a person's self-efficacy gives important information but provides only a partial picture of how behavior is influenced. Four sources of information upon which self-efficacy beliefs are based are; individual's own past performance, vicarious experiences of observing the performances of others, verbal persuasion that one possesses certain capabilities, and physiological state (Siegle \& McCoach, 2007). Zulkosky (2009) noted that a sense of self-efficacy can be gained as a person completes a skill successfully, observes someone else doing a task successfully, acquires positive feedback about completing a task, or relies on physiological cues. To Siegle and McCoach, (2007) capitalizing on the strongest of the above sources produces very confident individuals.

Self-efficacy is regarded to be context specific or the self evaluation or assessment of self through specifically defined situations (Sam, Othman, \& Nordin, 2005; Bandura, 1997). For the fact that self-efficacy is context specific one will be making mistake to think that self-efficacy in one area of an individual's life may translate in strong self-efficacy in another area of life. This occurs as a result of the fact that there may variances in ones' assessment of the four sources of information upon which self-efficacy is based. This is why Carroll, Houghton, Wood, Unsworth, Hattie, Gordon, and Bower (nd:4) stated that self-efficacy is best conceived as a 'differentiated set of self-beliefs specific to different areas of functioning (e.g., social self-efficacy, academic self-efficacy)'. Zimmerman (2000:83) has noted that the properties of selfefficacy are its level, generality and strength which are measured using questionnaire items that are task-specific, vary in difficulty and capture degrees of confidence, and he further stated that 'self-efficacy beliefs are not a single disposition but rather are multidimensional in form and differ on the basis of the domain of functioning'. In the same line of thought Zulkosky (2009) stated that self-efficacy is concerned about the self-perception or self-judgment of being able to accomplish a specific goal and cannot be sensed globally.

Several research works have been carried out to establish the relationship between self-efficacy and students' behaviours and achievement. Min-Hsun and Pey-Chewn (2012) found a significant positive correlation between language learning strategy use and self-efficacy beliefs of Taiwanese high school students. Participants used language learning strategies in a medium level, and held a medium level of self-efficacy belief. Lane, Lane and Cockerton (2003) found significant positive relationship between self-efficacy and postgraduate students' performance. Also in a study that involved increasing students' mathematics self-efficacy through teacher training, Siegle and McCoach (2007) found a significant relationship between self-efficacy and achievement of students whose teachers were trained in self-efficacy. This is to say that students whose teachers were trained in self-efficacy showed stronger relationship between posttest self-efficacy and posttest achievement than students of teachers who were not trained. Nicolaidou and Philippou (n.d) found stronger relationship between self-efficacy and achievement than attitude and achievement in mathematics. Ferla, Valcke and Cai (2009) in a study that examined the reconsideration of the structural relationship between self-efficacy and academic self-concept found out that academic self-concept is a better predictor (and mediator) for affective motivational variables while academic self-efficacy is better predictor (and mediator) for academic achievement. However, Sam, Othman, and Nordin (2005) found that higher levels of internet usage did not necessarily translate into better computer self-efficacy among undergraduates. They also found that computer self-efficacy was affected by disciplines of students. Lane, Lane, and Cockerton (2003) found relatively weak relationship between self-efficacy and performance.

According to Pajares (n.d), Bandura had drawn a distinction between the roles of self-efficacy beliefs versus those of outcome expectations in influencing motivation and predicting behavior. Self-efficacy beliefs are judgments of personal competence to engage in a behavior while outcome expectations are judgment of the likely consequence the behavior will produce. Schunk and Pajares (nd) pointed out that outcome expectations which are the consequences expected from one's own actions/behavior though are related to self-efficacy beliefs are not synonymous. They expatiated this by saying that an efficacious student may believe that she has the capability to learn mathematics but may equally belief that she will not score high in mathematics because of the instructor's disposition towards her in spite of her perceived capability. 
However, self-efficacy, according to Pajares, in part, determines outcome expectations. Students can as well judge or rate themselves on the likely consequence of their behavior, and come up with a position on the likely consequences of their efforts. In order to encourage self-regulated learning efforts are being made by contemporary evaluator to adopt assessment strategies that integrate students in the evaluation processes. In some cases, students are encouraged to rate themselves on the likely scores they will get in a task. This appraisal of self-knowledge as a function of score predictions, according to Tassone (2001) is an important component of the 'performance expectancy' which is considered to be part of self-regulated learning. Self-grading appears to result in increased students' learning (Sadler \& Good, 2006). Munoz and Alvarez (2007) had entertained the fears that students are inaccurate in their judgment of their abilities, occasioned by learners' unawareness of meta-cognitive skills (Kruger \& Dunning, 2009). When students selfrate themselves there is the tendency that they reflect on their performance and students who have high judgments of their personal competencies are likely to expect high positive consequence which their behavior will produce. KelberlauBerks (2006) found that students were accurate with their self-ratings and that those self-ratings helped students with test preparation. Wilson (1999) found positive correlation between adult German and French second language learners' selfratings and their performance in Test of English for International Communication (TOEIC).

Though researchers have studied predictive abilities of self-efficacy and some psychological constructs such as attitude (Nicolaidou \& Philippou, n.d), self-concept (Ferla, Valcke \& Cai, 2009), etc little has been done, more especially in Nigeria, to establish the predictive power of self-efficacy and self-rating as a function of score predictions on students' academic achievement. Hence, this study set out to investigate the extent self-efficacy and self-rating scores of students will predict their performance in an undergraduate degree examination. To address this issue, the following hypotheses were formulated:

- Ho1: Students' self-efficacy and self-rating scores do not have significant relationship with their academic achievement.

- Ho2: Students' self-efficacy and their self-rating scores do not combine to predict students' academic achievement.

- Ho3: Students' self-efficacy and their self-rating scores do not relatively predict students' academic achievement.

\section{Method}

The study adopted the correlational research design since the researchers are interested in determining the extent the predictor variables could determine the criterion variable and without the intension of manipulating any of the predictor variable.

The population of the study consisted of all the 133 Continuing Education Programme undergraduate students of the 2012/2013 academic who wrote the course - EDU 212 (Psychology of Learning). All the students were used. These are students who work and study and come to school during the weekend. They are off-campus college students. Traditionally, regular students are seen as better than these students and coupled with the fact that many of them are working and studying, they may lack the confidence to tackle their study.

The researchers constructed a domain-specific self-efficacy questionnaire with 20 items which were based on the course outlines used in teaching these students since strongest associations were found for those outcomes that were most similar to the way self-efficacy was measured (Lennon, 2010). Here, students were required to rate series of statements about their confidence in tackling some tasks in psychology of learning. The items had four-point scale response of strongly agree (SA), agree (A), disagree (D) and strongly disagree (SD) which show the extent of their confidence. And students were asked to complete the questionnaire immediately before they started writing their examination in the course (EDU 212). They were given 20 minutes to complete the self-efficacy questionnaire after which they were collected. After their written examination, they were asked to write the scores they would likely get in the examination. They were guided by the researchers by providing the marks allotted to each question in the examination rubrics. This would help them have an overview of lectures' making guide. 


\section{Results}

Table 1: Correlation matrix coefficient of students' self-efficacy, self-rating and academic achievement.

\begin{tabular}{|c|c|c|c|c|}
\hline & & self-efficacy & self-rating & achievement \\
\hline \multirow[t]{2}{*}{ self-efficacy } & Sig. (2-tailed) & 1 & $.206^{*}$ & .159 \\
\hline & & & .017 & .068 \\
\hline \multirow[t]{2}{*}{ self-rating } & Sig. (2-tailed) & $.206^{*}$ & 1 & $.203^{*}$ \\
\hline & & .017 & & .019 \\
\hline \multirow[t]{2}{*}{ Achievement } & Sig. (2-tailed) & .159 & $.203^{*}$ & 1 \\
\hline & & .068 & .019 & \\
\hline
\end{tabular}

Table 1 shows that there is a significant relationship between students' self-efficacy and self-rating scores. The product moment correlation coefficient $(r=.206, p<.05)$. Students' self-rating scores also has significant relationship with their academic achievement $(r=.203, p<.05)$. Therefore, we reject the hypotheses that there is no significant relationship between students' self-efficacy and self-rating, and between students' self-rating and their academic achievement. But the hypothesis that there is no significant relationship between self-efficacy and their academic achievement was upheld.

Table 2: Regression summary of composite contribution of self-efficacy and self-rating scores

\begin{tabular}{ccccc}
\hline Model & $\mathrm{R}$ & $\mathrm{R}$ Square & Adjusted R Square & Std. Error of the Estimate \\
& $.235^{\mathrm{a}}$ & .055 & .041 & 14.22408 \\
\hline
\end{tabular}

Table 2 shows that the multiple regression correlation coefficient indicating the relationship between the independent variable (students' self-efficacy and self-rating scores) and students' academic achievement is 0.055 . The adjusted $R$ square is 0.041 , meaning that the independent variables accounted for 4.1 percent variation in students' achievement. Further verification using multiple regression ANOVA produced $\mathrm{F}_{(2,130)}=3.809 ; \mathrm{P}<0.05$ meaning that there was a significant linear relationship between students' self-efficacy, self-rating score and students' academic achievement.

Table 3: Regression summary of the relative contribution of students' self-efficacy and self-rating scores

\begin{tabular}{lccccc}
\hline Model & Unstandardized Coefficients & \multicolumn{3}{c}{ Standardized Coefficients } \\
(Constant) & B & Std. Error & Beta & T & Sig. \\
self-efficacy & 19.590 & 10.373 & & 1.888 & .061 \\
self-rating & .172 & .123 & .122 & 1.401 & .163 \\
\hline
\end{tabular}

Table 3 above shows that only students' self-rating $(B=0.178, t(133)=2.038 ; P<0.05)$ was found to have significant relative contribution to students' achievement.

\section{Discussion}

The study attempted to find the predictive power of student's self-efficacy and self-rating scores as predictors of their achievement. The findings of the study showed that there is a significant positive relationship between students' selfefficacy and their self- rating scores $(r=.206, p<.05)$; between self-rating scores and academic achievement $(r=.203, p$ $<.05$ ); no significant relationship was found between self-efficacy and students' academic scores here.

The finding that significant positive relationship exists between self-efficacy and self-rating is in agreement with Pajeres (nd) that self-efficacy can, in a way, determine outcome expectation of students. That is to say that the consequences expected from one's own actions/behavior are related to one's judgments of personal competence to engage in a behavior. People who are confident in their abilities to perform a task expect higher outcome from the task engaged in. Again the significant relationship between self-rating scores and academic achievement indicates that people can accurately rate their expected consequences of their behaviours. This is in agreement with Wilson (1999) who found positive correlation between adult German and French second language learners' self-ratings and their performance in Test of English for International Communication (TOEIC), and Berks' (2006) finding that students were 
accurate with their self-ratings. Furthermore, the finding that there is no significant correlation between self-efficacy and students' academic achievement contrasts sharply with the findings of Min-Hsun and Pey-Chewn (2012), Lane, Lane and Cockerton (2003), and Siegle and McCoach (2007). Literature has shown significant positive relationship than no significant relationship between self-efficacy and academic achievement, and this calls for the examination of other variables that might have interfered here. Performances can be altered by variables such as self-regulatory skills of students. Bandura (2006) noted that proficient performance is in a way guided by higher-order self-regulatory skills which include generic skills for diagnosing task demands, constructing and evaluating alternative courses of action, setting proximal goals to guide one's efforts, and creating self-incentives to sustain engagement in taxing activities and to manage stress and debilitating intrusive thoughts. This group of students may lack necessary self-regulatory skills that would have enabled them match their self-efficacy with their achievement. This might have been the result of insufficient knowledge or efforts by the students. Pajeres (2002) in wik.ed.uiuc.edu emphasized that large amount of self-efficacy cannot counteract limited skills and knowledge.

Again, findings showed that the two variables (self-efficacy and self-rating scores) when combined together using multiple regression could not predict significantly students' academic achievement. They could account for only $4 \%$ percent of variation in students' achievement. However, in examining the relative contributions of the two variables table 3 indicated that self-rating scores predicted students' achievement more than their self-efficacy. This discrepancy in prediction also confirms the fact that though the two variables are related that they are not synonymous.

\section{Conclusion}

The work has indicated a relationship between self-efficacy and self-rating; self-rating and students' achievement but no relationship between self-efficacy with students' achievement; that self-efficacy did not predict their academic achievement while self-rating scores did. And the significant relationship between self-efficacy and their self-rating implies that the more ones self-efficacy belief increase, the more his outcome expectation will also increase. Students, who perceived themselves as having the confidence to perform the task, also expected higher results after the task. However, though there was positive linear relationship between self-efficacy and their academic performance, the relationship was not significant, but significant relationship existed between self-rating and academic achievement. This implies that some variables might have mediated between self-efficacy and students' academic achievement. These may include the nature of the examination, students' attribution mechanism, and skills in self-regulated learning. This points to the fact that one's perception of one's ability is not enough to counter insufficient knowledge in the area.

\section{References}

Bandura, A. (1997). Self-efficacy: The exercise of control. New York: Freeman.

Bandura, A. \& Locke, E. A. (2003). Negative self-efficacy and goal effects revisited. Journal of Applied Psychology, 88,( 1), 87-99.

Carroll, A. , Houghton, J., Wood, R. Unsworth, K., Hattie, J., Gordon, L., \& Bower, J. (nd). Self-efficacy and academic achievement in Australian high school students: The mediating effects of academic aspirations and delinquency. www.ncbi.nlm.nih.gov/pubmed/19027942

Clark, N. M. \& Dodge, J. A. (1999). Exploring self-efficacy as predictor of disease management. Health Education and Behaviour, 26, (1), 72-89.

Ferla, J., Valcke, M. \& Cai, Y. (2009). Academic self-efficacy and academic self-concept: Reconsidering the structural relationships. Learning and Individual Differences, 19, 499-505.

Hall, S. \& Vance, E. A. (2010). Improving self-efficacy in Statistics: Role of self-explanation and feedback. Journal of Statistics Education, 18, (3), 1-22.

Harrison, A. W., Rainer, R. K, Hochwarter, W. A. \& Thompson, K. R. (1997). Testing the self-efficacy-performance linkage of socialcognitive theory. The Journal of Social Psychology, 37(I), 79-87

Kelberlau-Berks, D. R. (2006). The effects of self-assessment on student learning. A Report On Action Research Project Submitted in the Middle Institute Partnership And Mat Degree,Lincoln, Nebraska.

Lane, J., Lane, A. \& Cockerton, T. (2003). Prediction of postgraduate performance from self-efficacy, class of degree and cognitive ability test scores. www.heacademy.ac.uk/assets/hlst/documents/.../0016_lanej_vol2no1.

Lennon, J. M. (2010). Self-efficacy. In J. A. Rosen, E. J. Glennie, B. W. Dalton, J. M. Lennon, \& R. N. Bozick (Eds). Noncognitive Skills in the Classroom: New Perspectives on Educational Research. RTI Press publication No. BK-0004-1009.Research Triangle Park, NC: RTI International. Retrieved [date] from http://www.rti.org/rtipress.

Min-Hsun, S. \& Pey-Chewn, D. (2012). EFL learners' language learning strategy use and perceived self-efficacy. European Journal of Social Sciences, 27, (3), 335-345.

Munoz, A. \& Alvarez, M. E. (2007). Students' objectivity and perception of self-assessment in an ELF classroom. The Journal of Asia 
TEFL, 4 (2), 1-25.

Nicolaidou, M. \& Philippou, G. (n.d). Attitudes towards mathematics, self-efficacy andachievement in problem-solving. European Research in Mathematics III. www.ijhssnet.com/journals/Vol_1_No_15_Special_Issue.../34

Pajares, F. (n.d). Current directions in self-efficacy research. In $\bar{M}$. Maehr \& P. R. Pintrich (Eds). Advances in motivation and achievement. Greenwich, CT: JAI Press. http://www.desemory.edu/mfp/BanEney.html.

Sam, H. K. Othman, A. E. A. \& Nordin, Z. S. (2005). Computer self-efficacy, computer anxiety, and attitude toward the internet: A study among undergraduates in Unimas Educational Technology and Society, 8, (4), 205-219.

Sandler, P. M. \& Good, E. (2006). The impact of self- and peer-grading on student learning. Educational Assessment, 11, (1), 1-31.

Schunk, D. H., \& Pajares, F. (2002). The development of academic self-efficacy. In A. Wigfield \& J. Eccles (Eds.), Development of achievement motivation (pp. 16-32). San Diego, CA: Academic Press.

Siegle, D. \& McCoach, D. B. (2007). Increasing student mathematics self-efficacy through teacher training. Journal of Advanced Academics, 18, (2), 278-312.

Stretcher, V. J., DeVellis, B. M., Becher, M. H. \& Rosenstock, I. M. (1986). The role of self-efficacy in achieving health behavior change. Health Education Quarterly, 73-91.

Self-efficacy. wik.ed.uiuc.edu/articles/s/e/l/self-efficacy.html

Tassone, A. (2001). The explicit use of performance expectancy as a function of self-regulated learning. A thesis submitted in the Faculty of Education, Lakehead University, Thunder Bay, Ontario.

Wilson, K. M. (1999). Validity of global self-ratings of ESL speaking proficiency based on an FSI/ICR-referenced scale. Princeton: Educational Testing Services, Statistics and Research Division.

Zimmerman, B. J. (2000).Self-efficacy: An essential motive to learn. Contemporary Educational Psychology 25, 82-91.

Zulkosky, K. (2009). Self-efficacy: A concept analysis. Nursing Forum, 44, (2), 93-102. 